\title{
Changes in Blood Gas Tensions and Functional Residual Capacity in Chronic Asthmatics Treated with Disodium Cromoglycate
}

\author{
D. J. LANE,* B.M., B.CH., M.R.C.P.
}

$S^{-10}$ ummary: Twenty chronic asthmatic subjects were treated with disodium cromoglycate in open trial. Although in the group as a whole spirometric findings improved, some patients showed a significant increase in arterial oxygen tension or a significant fall in functional residual capacity without any appreciable changes in spirometry. These changes may partly explain the clinical efficacy of this drug.

\section{Introduction}

Published trials concerning the clinical use of disodium cromoglycate have, apart from one exception (Grant, Channell, and Drever, 1967), reported that considerable subjective benefit can be expected from the use of this drug in bronchial asthma (Howell and Altounyan, 1967; Kennedy, 1967 ; Morrison Smith and Devey, 1968; Moran, Bankier, and Boyd, 1968 ; Kidner, Meisner, Pride, and Bruce Pearson, 1968 ; Robertson, Epstein, and Warrell, 1969). On the whole these trials have not included any more complex tests of functional disturbance than can be obtained from simple spirometry-that is, forced vital capacity (F.V.C.) and one-second forced expiratory volume (F.E.V..$_{1}$ ). The changes reported in these tests after treatment have been variable and, in relation to the clinical improvement, disappointing. The recent trial of Robertson et al. (1969) included measurements of airways resistance by body plethysmography and showed a fall in resistance on treatment with disodium cromoglycate. This index, however, was no more discriminative than simple spirometry, and daily peak flow measurements were shown to be as reliable an index of change as any other.

It has been suggested that alterations in measurements of pulmonary function, other than spirometry, may explain the subjective improvement. The present investigation was undertaken to measure changes in blood gases and functional residual capacity (F.R.C.) in a group of patients receiving disodium cromoglycate in open trial.

\section{Methods}

Twenty patients ( 8 men and 12 women) were studied. They were chronically disabled by bronchial asthma and were either attending the hospital outpatient department for management of steroid or other therapy or were referred directly by their general practitioners. Their ages ranged from 21 to 66 years (mean 48.4). A diagnosis of allergic asthma was based on clinical history, including previous experience that corticosteroid therapy had been beneficial, and on response to bronchodilators. The mean improvement in F.E.V. . $_{1}$ following isoprenaline inhalation in the basal studies was $33 \pm 17 \%$. Those showing an improvement of less than $30 \%$ with isoprenaline were tested with atropine; all showed a poor response compared with that to isoprenaline, this being a characteristic finding in allergic airways obstruction (Altounyan, 1964). Tests of cutaneous hypersensitivity were not made.

Each patient was tested before and at the end of a two-week period on Intal compound (disodium cromoglycate $20 \mathrm{mg}$. and

* Lecturer in Medicine, Nuffield Departments of Medicine and Anaesthetics, the Radcliffe Infirmary, Oxford. isoprenaline $0.1 \mathrm{mg}$.). No documentary evidence on the subjective effect of the drug was made, but each patient was asked to comment on his experience while receiving the drug compared with previous therapy.

The drug was given four times daily to most patients, though six capsules a day were recommended for those with severe asthma (F.E.V. $<0.8$ 1.). Other therapy was mostly kept constant, though patients on steroids or those taking frequent inhalations from isoprenaline aerosols were advised to reduce the dose of these if possible.

Spirometry.-This was carried out with a Med-Science Wedge Spirometer (model 370) having a computed digital readout of F.V.C., F.E.V., F.E.V., and P.F. On a few occasions a Vitalograph was substituted, this having been previously calibrated against the Wedge Spirometer.

Blood Gas Tensions.-Standard Radiometer electrodes were used with direct electrical readout on E.I.L. Vibron equipment for $\mathrm{PCO}_{2}$ and $p \mathrm{H}$, and digital readout for $\mathrm{Po}_{2}$ (Hahn, 1969). Samples were taken into a $10-\mathrm{ml}$. plastic syringe by direct arterial puncture of the brachial artery in the antecubital fossa. Analysis was carried out within 15 minutes, gas tensions being corrected for elapsed time and temperature according to the nomogram of Kelman and Nunn (1966).

Ventilation.-Expired gas was collected into a polyethylene Douglas bag with a two-way gravity flap valve. Volumes were measured with a gas clock and gas tensions with electrodes as above.

F.R.C.-Nitrogen washout with $100 \% \mathrm{O}_{2}$ was followed for seven minutes, a Med-Science Nitralyser (model 305AR) being used to measure breath-by-breath nitrogen $\left(\mathrm{N}_{2}\right)$ changes at the mouth and mixed expired $\mathrm{N}_{2}$. For the calculation of F.R.C. an initial alveolar $\mathrm{N}_{2}$ of $81 \%$ was assumed and $\mathrm{N}_{2}$ washout from the tissues was taken from the data of Cournand, Yarmush, and Riley (1941). The index of gas-mixing efficiency suggested by Becklake (1952) was calculated and the alveolar $\mathrm{N}_{2} \%$ at the end of seven minutes noted.

\section{Results}

A statistical analysis of the findings is given in the Table and the changes in spirometry, $\mathrm{PaO}_{2}$, and F.R.C. are shown in Figs. 1 and 2.

Statistical Analysis of Changes in Pulmonary Function on Treatment with Disodium Cromoglycate in 20 Patients with Chronic Bronchial Asthma

\begin{tabular}{|c|c|c|c|c|}
\hline & $\begin{array}{l}\text { No. of } \\
\text { Cases }\end{array}$ & Basal & $\begin{array}{c}\text { On } \\
\text { Intal }\end{array}$ & Significance \\
\hline 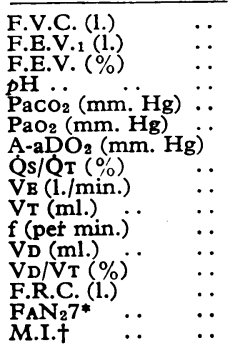 & $\begin{array}{l}20 \\
20 \\
20 \\
17 \\
18 \\
17 \\
17 \\
17 \\
17 \\
17 \\
17 \\
17 \\
18 \\
19 \\
16 \\
11\end{array}$ & $\begin{array}{c}2 \cdot 36 \pm 0 \cdot 83 \\
1 \cdot 10 \pm 0.56 \\
45 \cdot 2 \pm 11 \cdot 3 \\
7 \cdot 420 \pm 0 \cdot 046 \\
41 \cdot 0 \pm 7 \cdot 8 \\
66 \cdot 3 \pm 7 \cdot 1 \\
40 \cdot 1 \pm 6 \cdot 2 \\
17.4 \pm 6 \cdot 9 \\
11 \cdot 0 \pm 3 \cdot 8 \\
645 \pm 260 \\
17 \cdot 0 \pm 4 \cdot 4 \\
278 \pm 102 \\
46 \cdot 4 \pm 7 \cdot 7 \\
4 \cdot 10 \pm 1 \cdot 44 \\
0.043 \pm 0.021 \\
10.9 \pm 3.7\end{array}$ & $\begin{array}{c}2 \cdot 81 \pm 0 \cdot 89 \\
1 \cdot 41 \pm 0 \cdot 71 \\
48 \cdot 3 \pm 13 \cdot 6 \\
7 \cdot 418 \pm 0 \cdot 052 \\
40 \cdot 1 \pm 6 \cdot 2 \\
73 \cdot 2 \pm 10 \cdot 8 \\
35 \cdot 5 \pm 8 \cdot 5 \\
13 \cdot 6 \pm 7 \cdot 9 \\
10 \cdot 8 \pm 2 \cdot 5 \\
671 \pm 241 \\
16 \cdot 1 \pm 5 \cdot 6 \\
280 \pm 94 \\
42 \cdot 8 \pm 9 \cdot 9 \\
3.47 \pm 0 \cdot 91 \\
0.041 \pm 0 \cdot 010 \\
11 \cdot 1 \pm 4 \cdot 9\end{array}$ & $\begin{array}{c}P<0.002 \\
P<0.001 \\
\text { N.S. } \\
\text { N.S. } \\
\text { N.S. } \\
P<0.002 \\
P<0.05 \\
P<0.01 \\
\text { N.S. } \\
\text { N.S. } \\
\text { N.S. } \\
\text { N.S. } \\
\text { P }<0.002 \\
\text { P }<0.01 \\
\text { N.S. } \\
\text { N.S. }\end{array}$ \\
\hline
\end{tabular}

Alveolar nitrogen after seven minutes' washout with $100 \% \mathrm{O}$. t Becklake mixing index. 
Improvement in spirometry on disodium cromoglycate was seen in most patients, the F.V.C. increasing by more than 0.251 . in $14(70 \%)$ and the F.E.V. by more than 0.101 . in 15 patients $(75 \%)$. Though other patients showed a deteriora-
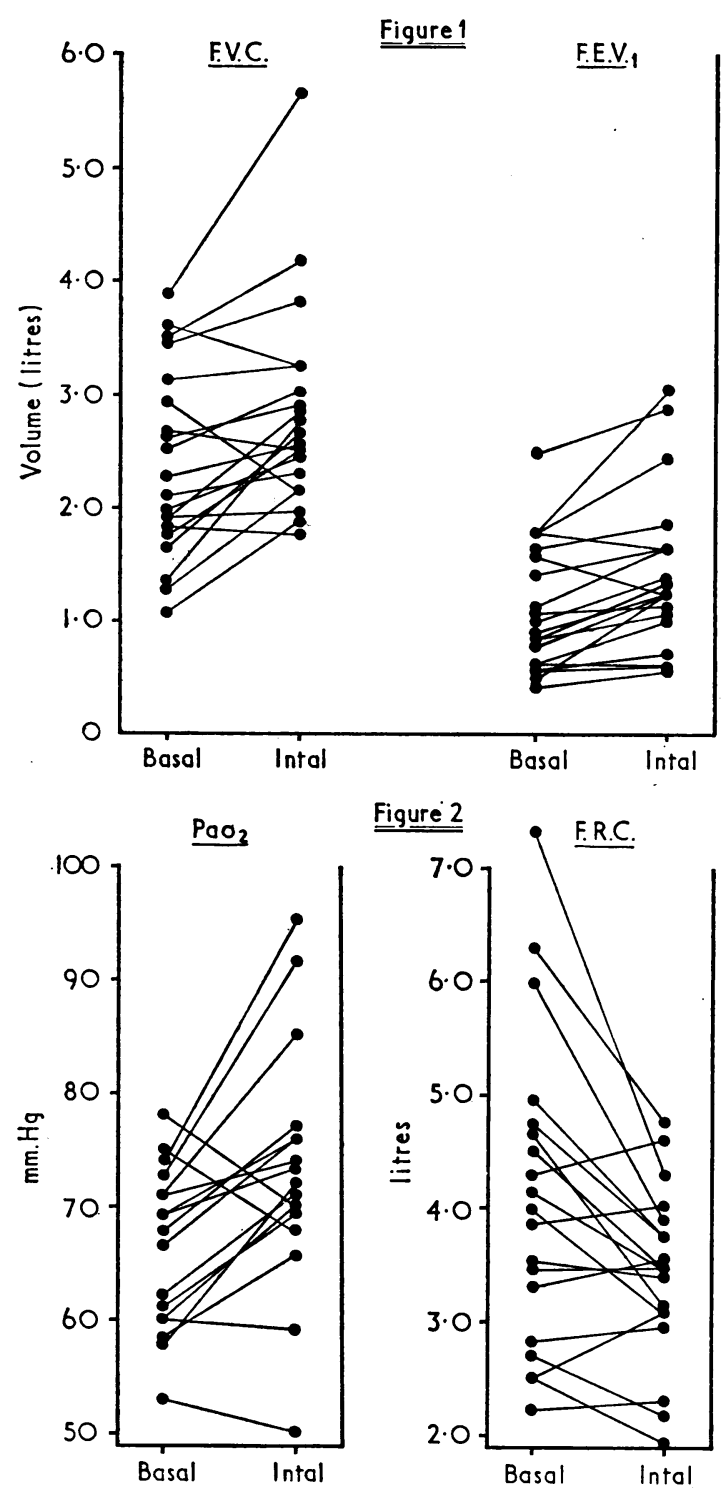

FIG. 1.-Changes in F.V.C. and F.E.V. 1 on treatment with disodium cromoglycate in 20 patients with chron:c asthma. FIG. 2. Changes in $\mathrm{P}_{8} \mathrm{O}_{3}$ and F.R.C. on treatment with disodium cromoglycate in patients with chronic asthma.

tion or no change in spirometry, the mean changes for the group were statistically significant (see Table). An overall improvement in $\mathrm{PaO}_{2}$ was also found, the mean level rising from 66.3 to $73.2 \mathrm{~mm}$. $\mathrm{Hg}(\mathbf{P}<0.002)$. There was no significant change in $\mathrm{PaCO}_{2}$ or $\mathrm{pH}$. The alveolar-arterial $\mathrm{Po}_{2}$ gradient decreased significantly, and the fall in estimated venous admixture was also significant. The change in $\mathrm{PaO}_{2}$ was positively correlated with the change in F.E.V. $(r=0.67$; Fig. 3$)$ but was not related to any other indices measured.

The F.R.C. showed variable changes from a fall of 3.201 . to a rise of 0.571 ., with 10 patients $(50 \%)$ showing a fall in F.R.C. of more than 0.51 ; the mean change for the group was significant (4.10 to 3.47 1., $\mathrm{P}<0.01)$. Changes in F.R.C. were

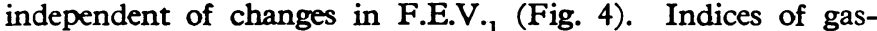
mixing derived from the $\mathrm{N}_{2}$ washout data obtained during the measurement of the F.R.C. showed no significant change.

Of the ventilatory data only dead-space/tidal-volume ratio showed any appreciable directional change. There was no significant change in ventilation, tidal volume, frequency, or physiological dead space. No striking relation could be found between the ventilatory data and other indices measured.

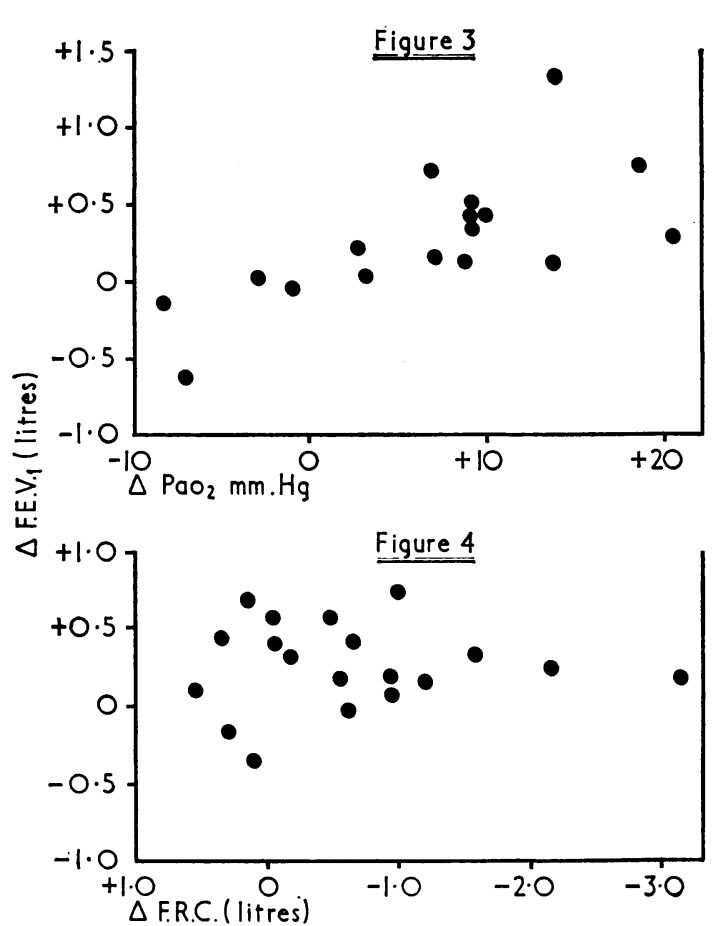

Fig. 3.-Relation between changes in $\mathrm{P}_{\mathrm{a}} \mathrm{O}_{2}$ and in F.E.V. 1 on treatment with disodium cromoglycate.

FIG. 4.- Relation between changes in F.R.C. and in F.E.V.1 on treatment with disodium cromoglycate.

Subjective improvement was recorded in 15 patients $(75 \%)$. ํํㅇ This could be said to be dramatic in four. Five showed no change or only slight improvement. All four patients on steroids tolerated a lower dose while receiving disodium cromo-市 glycate but none could stop steroids altogether.

\section{Discussion}

In previous trials the encouraging improvement in subjective criteria on treatment with disodium cromoglycate has been associated with variable and, on the whole, disappointing changes in simple pulmonary function tests. Though Morrison Smith and Devey (1968) reported a $66 \%$ improvement in F.E.V..$_{1}$ in children, Grant et al. (1967) and Moran et al. (1968) found no significant change in adults. The improvement in 0 F.E.V. ${ }_{1}$ recorded for this group of $28 \%$ (mean figures $1 \cdot 10 \mathrm{~N}$ to 1.411 .) is in accord with the results of Altounyan and Howell 0 (1967) and Kidner et al. (1968). Changes in F.V.C. were given $\frac{D}{0}$ by Morrison Smith and Devey (1968) and commented on by Kidner et al. (1968). Other trials did not analyse their data $N$ in this respect. Changes in F.V.C. were similar to those in F.E.V..$_{1}$ in most patients in this series and do not appear to응 afford a separate index for analysis.

Breathing at high lung volumes is costly in terms of respira-

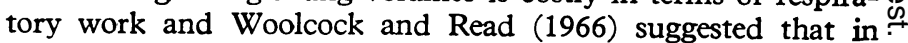
bronchial asthma a fall in F.R.C. may be associated with clinical 0 improvement despite little change in F.E.V.1. A fall in F.R.C. on treatment with disodium cromoglycate was noted in most $\stackrel{\mathbb{Q}}{\stackrel{9}{\circ}}$ of the patients studied by Robertson et al. (1969). F.R.C. was $\stackrel{\mathbb{D}}{\mathbb{2}}$ measured in 19 of the patients included in this study. Apart from those patients who showed little change in either F.R.C. 8 or F.E.V..$_{1}$, there was a tendency for some patients showing only a small change in F.E.V. to have an appreciable fall in F.R.C. (Fig. 4). Of seven patients who had a fall in F.R.C. greater than 0.91 , six showed an increase in F.E.V..$_{1}$ of less than 0.281 . These observations support the suggestion that improvement on disodium cromoglycate may be associated with 
a considerable fall in F.R.C. when there is little change in F.E.V. ${ }_{1}$

Direct measurement of airways resistance was not undertaken in this study, but, in addition to spirometric measurements, some idea of changes in airways calibre may be indirectly obtained from measuring the blood gas tensions and intrapulmonary gas-mixing. Levels of $\mathrm{PaCO}_{2}$ are unlikely to be sensitive to changes in airways calibre because central and peripheral chemoreceptors maintain $\mathrm{PaCO}_{2}$ normal, except in patients with neuromuscular damage or severe chronic bronchitis. In accordance with this no significant change was found in either $\mathrm{PaCO}_{2}$ or $p \mathrm{H}$. On the other hand, small changes in peripheral airways resistance, not detectable in terms of F.E.V. 1 or specific airways conductance, may be reflected in individual alveolar ventilation/perfusion ratios and so in the level of arterial oxygenation. This was most clearly seen in the highly significant improvement in $\mathrm{PaO}_{2}$. The $\mathrm{PaO}_{2}$ changes correlated fairly well with the F.E.V..$_{1}$ changes (Fig. 3), but six patients still showed an improvement in $\mathrm{PaO}_{2}$ of between 9 and $21 \mathrm{~mm}$. $\mathrm{Hg}$ when their F.E.V. ${ }_{1}$ increase was less than $0.44 \mathrm{l}$. This tendency for $\mathrm{PaO}_{2}$ to improve in the absence of great change in the F.E.V. ${ }_{1}$ was especially pronounced in patients with an initial F.E.V..$_{1}$ of less than 1.101 . and an initial $\mathrm{PaO}_{2}$ of less than $65 \mathrm{~mm}$. $\mathrm{Hg}$. This raises the possibility that in bronchial asthma the relaxation of peripheral bronchiolar spasm leading to better oxygenation may be an important mode of recovery from a state of severe obstruction. Such a change would not necessarily be reflected in a significant rise in F.E.V..$_{1}$.

A similar discrepancy between changes in $\mathrm{PaO}_{2}$ and in F.E.V. was noted by Rees, Millar, and Donald (1968), who followed a group of asthmatic patients recovering from an episode of status asthmaticus. They found that an improvement of 1.01 . in F.E.V. was associated with changes in $\mathrm{PaO}_{2}$ which varied from a fall of $5 \mathrm{~mm}$. $\mathrm{Hg}$ to an increase of over $40 \mathrm{~mm}$. $\mathrm{Hg}$. Despite this, a positive correlation was shown between the change in F.E.V..$_{1}$ and the change in $\mathrm{PaO}_{2}$, which has a slope not significantly different from that in Fig. 3 of this paper. These results may be contrasted with the acute effects of isoprenaline and aminophylline, where, because of action on the pulmonary vasculature, there may be either little change or a fall in $\mathrm{PaO}_{2}$ in association with an improvement in F.E.V..$_{1}$ (Halmagyi and Cotes, 1959 ; Palmer and Diament, 1967 ; Tai and Read, 1967). The small amount of isoprenaline contained in the Intal compound capsules used in this trial $(0.1 \mathrm{mg}$.) is unlikely to have influenced the results, since the tests were always carried out more than two hours after the last capsule had been given. By this time the acute effects of isoprenaline would have passed off.

There was no significant correlation between changes in $\mathrm{PaO}_{2}$ and changes in F.R.C., so that it is unlikely that these two measurements express alterations in the same underlying pathological process. Neither was there any correlation between changes in $\mathrm{PaO}_{2}$ and changes in minute ventilation, so it seems unlikely that subjective improvement can be attributed to relief from a hypoxic drive.
Changes in peripheral airway calibre should also be reflected in indices of gas mixing. The $\mathrm{N}_{2}$ washout curves were analysed by the method of Becklake (1952), and in terms of the level of alveolar $\mathrm{N}_{2}$ achieved at seven minutes. Neither index showed a significant change, and the reason for this may be technical. A critical appraisal of $\mathrm{N}_{2}$ washout data by Cumming and Jones (1966) suggested that the measurement can be made reproducible and quantitatively reliable only if expressed in terms of the quantity of exhaled nitrogen rather than in terms of end tidal $\mathrm{N}_{2} \%$. It seems unlikely, therefore, that any conclusions about gas-mixing can be drawn from the present observations.

In conclusion it is suggested that an improvement in $\mathrm{PaO}_{2}$ and/or F.R.C. may partly explain findings of subjective improvement on treatment with disodium cromoglycate when there has been little change in spirometry. It is not suggested that these changes are the result of some specific action of this drug but that they represent two modes of recovery from a state of severe airways obstruction which need not be associated with dramatic changes in spirometry. The value of disodium cromoglycate would appear to be in its ability to induce these changes in patients previously chronically disabled by bronchial asthma without resort to potentially dangerous doses of corticosteroids.

I wish to thank the physicians of the Radcliffe Infirmary for allowing me to study patients under their care, and Professor A. Crampton-Smith for helpful advice and encouragement. The technical help of Miss M. Hodges is gratefully acknowledged.

This work was supported by a grant from the Nuffield Committee for Medical Research.

Altounyan, R. E. C. (1964). Thorax, 19, 406.

Altounyan, R. E. C., and Howell, J. B. L. (1967). Proceedings of 2nd International Symposium on Tuberd Bronchitis, Davos, 1967 . In press.

Becklake, M. R. (1952). Thorax, 7, 111

Cournand, A., Yarmush, I. G., and Riley, R. L. (1941). Proceedings of the Society for Experimental Biology and Medicine, 48, 280.

Cumming, G., and Jones, J. G. (1966). Respiration Physiology, 1, 238.

Grant, I. W. B., Channell, S., and Drever, J. C. (1967). Lancet, 2, 673.

Hahn, C. E. W. (1969). Fournal of Scientific Instruments, 2, 48.

Halmagyi, D. F., and Cotes, J. E. (1959). Clinical Science, 18, 475.

Howell, J. B. L., and Altounyan, R. E. C. (1967). Lancet, 2, 539.

Kelman, G. R., and Nunn, J. F. (1966). Fournal of Applied Physiology, 21, 1484 .

Kennedy, M. C. S. (1967). Lancet, 2, 838.

Kidner, P. H., Meisner, P., Pride, N. B., and Pearson, R. S. B. (1968). Lancet, 2, 655.

Moran, F., Bankier, J. D. H., and Boyd, G. (1968). Lancet, 2, 137.

Palmer, K. N. V., and Diament, M. L. (1967). Lancet, 2, 383

Rees, H. Millar, J. S., and Donald, K. W. (1968). Quarterly fournal of Medicine, 37, 541.

Robertson, D. G., Epstein, S. W., and Warrell, D. A. (1969). British Medical fournal, 1,552 .

Smith, J. M., and Devey, G. F. (1968). British Medical Fournal, 2, 340.

Tai, E., and Read, J. (1967). Thorax, 22, 543.

Woolcock, A. J., and Read, J. (1966). American fournal of Medicine, 41, 259 . 